\title{
ESTUDO DA TERMÓLISE DE LEVEDURAS Saccharomyces cerevisiae DE USINA DE ÁLCOOL USANDO ENERGIA DE MICROONDAS
}

\author{
ANTONIO MARSAIOLI JUNIOR * \\ ZILDA DORATIOTTO DE SALLES ARÉVALO **
}

\begin{abstract}
Estudou-se a termólise de leveduras Saccharomyces cerevisiae, mediante tratamento em microondas, variando-se os parâmetros de temperatura e tempo de exposição. A resposta pesquisada foi o efeito térmico (termólise) sobre as células, mediante verificação do rendimento de extração da proteína, da sua avaliação nutricional (digestibilidade) e da viabilidade celular. Conseguiuse valores de $38 \%$ de extração da proteína, digestibilidade situada na faixa de 32 a $85 \%$ e zero de viabilidade das células.
\end{abstract}

\section{INTRODUÇÃO}

Dentre os produtos que podem substituir os suplementos convencionais, usados na alimentação animal, destacam-se os microorganismos (algas, bactérias, fungos e leveduras), considerados como fontes de proteína unicelular. $O$ interesse na utilização de microorganismos na alimentação, tanto humana como animal, deve-se, entre outros motivos, à sua velocidade de crescimento, à possibilidade de cultivo em substratos diversos e também ao seu elevado teor protéico.

O Brasil constitui-se no maior produtor mundial de álcool de cana-deaçúcar, com produção estimada de 13,5 bilhões de litros por ano. Desta forma, assume posição privilegiada quanto à disponibilidade dos subprodutos obtidos no processamento de cana-de-açúcar, notadamente a levedura, que pode ser utilizada na alimentação humana e animal (CARVALHO, 2000).

Embora a levedura seca de álcool possa ser utilizada como fonte protéica, o material constituinte da parede das células é indesejável, por reduzir o

* Professor, Doutor em Engenharia de Alimentos, Departamento de Engenharia de Alimentos (DEA), Faculdade de Engenharia de Alimentos (FEA), Universidade Estadual de Campinas (UNICAMP), Campinas, SP. (e-mail: tonymars@ceres.fea.unicamp.br).

** M.Sc. em Engenharia de Alimentos, Universidade Estadual do Tocantins (UNITINS), Paraíso do Tocantins, TO. (e-mail: zdoratiotto@hotmail.com). 
valor biológico da massa celular. Além disso, a ingestão de células intactas também pode provocar distúrbios gastro-intestinais (MOURA, 1986).

Tornar-se imperativo portanto, o isolamento da proteína para melhorar sua digestibilidade, a partir do desenvolvimento de métodos de processamento da biomassa que visem a ruptura celular. Uma das possibilidades para sua ruptura é a termólise, que consiste na inativação das células de levedura pela ação do calor. A termólise consiste em etapa anterior à secagem. Poucas informações existem sobre as leveduras, quando submetidas à ação do calor, visando sua secagem e/ou inativação. Também não foram encontrados trabalhos anteriores sobre a termólise de leveduras usando a energia de microondas.

A composição química das leveduras (Tabela 1) depende de diversos fatores, tais como: natureza do substrato utilizado, grau de aeração do substrato, espécie de levedura, tratamentos impostos ao meio de cultura e concentração de sais (KRIDER et al. 1982). Dentre estes o substrato utilizado é o mais importante, afetando tanto a taxa de crescimento, como a composição, principalmente em proteínas e lipídios (VANANUVAT \& KINSSELA, 1975).

\section{TABELA 1 - COMPOSIÇÃO QUÍMICA DE MICROORGANISMOS UNICELULARES (BASE SECA)}

\begin{tabular}{l|c|c|c}
\hline & Fungos & Leveduras & Bactérias \\
\hline Proteína & $31-50$ & $47-56$ & $72-93$ \\
\hline Ácidos nucléicos & 9,2 & $6-15$ & $8-16$ \\
\hline Cinzas & $9-14$ & $5-9,5$ & $3-7$ \\
\hline Lipídios & $2-8$ & $2-6$ & $1,5-3$ \\
\hline
\end{tabular}

Fonte: REED \& NAGODAWITHANA (1991).

As leveduras contam com 50 a $70 \%$ de proteína bruta em base seca, sendo que aproximadamente $20 \%$ desta contém nitrogênio não protéico, representado basicamente por ácidos nucléicos que apresentam de 8 a 12\% do nitrogênio total (BRESSANI, 1968 e REED \& PEPPLER, 1973).

As paredes das células são resistentes às enzimas digestivas, tornando os componentes intracelulares indisponíveis. Segundo KIHLBERG (1972) e KINSELLA \& SHETTY (1978), a autólise tem sido utilizada para romper a parede celular pela ação de enzimas endógenas. A plasmólise e a hidrólise têm sido empregadas para preparação de extratos usados como agentes flavorizantes (KIHLBERG, 1972). Mediante combinação de tratamentos mecânico e químico, OKEZIE \& KOSIKOWISKI (1981) obtiveram o 
rompimento de células de levedura Cândida tropicalis com rendimento de $71 \%$ na extração de proteína celular.

O método de ruptura mecânica tem sido muito utilizado, principalmente quando se deseja obter produtos (extratos protéicos) com boas propriedades funcionais, permitindo recuperação eficiente da proteína mais próxima ao seu estado nativo, pois evita o uso de tratamentos térmicos drásticos, ajustes de pH e adição de reagentes químicos (HEDENSKOG \& MOGREN, 1973). A desintegração mecânica pode ser conduzida por vários meios, como homogeneizador convencional, desintegrador de alta pressão, exposição ao ultra-som e desintegrador tipo moinho de bolas (ENGLER,1979).

As microondas são caracterizadas como um tipo de onda eletromagnética que ocupa, no espectro de freqüências, a posição situada entre $300 \mathrm{MHz}$ e $300 \mathrm{GHz}$. As microondas constituem forma de radiação eletromagnética que apresenta propriedades similares às da luz visível, mas distinguem-se pelo comprimento de onda que é aproximadamente $10^{5}$ vezes maior. Tal disparidade exige técnicas completamente diferentes para a geração, transporte, detecção e uso dos campos de microondas em relação às técnicas de óptica (MARSAIOLI, 1991). As freqüências de $915 \mathrm{MHz}$ e $2450 \mathrm{MHz}$ são utilizadas para aplicações térmicas das microondas na indústria, ciência e medicina.

STARON et al. (1980) publicaram trabalho sobre a ação de microondas na inativação de células de microorganismos, embora não tenham mencionado a temperatura alcançada pelas amostras, nem a concentração inicial de células (Tabela 2).

\section{TABELA 2 - AÇÃO DE MICROONDAS EM TRÊS TIPOS DE MICROORGANISMOS (EM \% DE GERMES INTÁCTOS)}

\begin{tabular}{c|c|c|c}
\hline $\begin{array}{c}\text { TEMPO } \\
\text { (segundos) }\end{array}$ & $\begin{array}{c}\text { Trichoderma } \\
\text { album }\end{array}$ & $\begin{array}{c}\text { Geotrichum } \\
\text { candidum }\end{array}$ & $\begin{array}{c}\text { Saccharomyces } \\
\text { cerevisiae }\end{array}$ \\
\hline 30 & 50 & 80 & 80 \\
60 & 0 & 25 & 15 \\
90 & 0 & 5 & 2 \\
150 & 0 & 0 & 0 \\
\hline
\end{tabular}

O objetivo do presente trabalho consistiu em verificar os efeitos de microondas sobre a termólise da levedura, obtida em usina de álcool, usando a temperatura e o tempo do tratamento como parâmetros. Estudou-se o efeito térmico sobre as células mediante verificação do rendimento de extração da proteína, da sua avaliação nutricional (digestibilidade) e da viabilidade das células. 


\section{MATERIAL E MÉTODOS}

\subsection{MATERIAL}

Foi utilizado leite de levedura recuperado, fornecido por uma usina de álcool, cujas amostras apresentavam $85 \%$ de umidade e $\mathrm{pH}$ entre 4,0 a 4,3 .

Para o processamento das amostras, com $100 \mathrm{~mL}$ cada, usou-se forno digestor de microondas, operando na freqüência de $2450 \mathrm{MHz}$, potência programável de zero à máxima de $950 \mathrm{~W}$, fabricado pela CEM Corporation, modelo MDS-2100, para aquecimento rápido de até 12 amostras.

\subsection{MÉTODOS}

O leite de levedura recebeu o tratamento térmico no forno de microondas. As amostras, cujo volume variou entre 80 e $120 \mathrm{~g}$, foram distribuídas em quatro provetas, para cada ciclo de operação. Para os valores de temperaturas $\left(80,90,110,120\right.$ e $125^{\circ} \mathrm{C}$ ) e tempos (15 e 30 minutos) pesquisados, as potências de microondas aplicadas às amostras permaneceram dentro da faixa de 25 a $40 \%$ da potência máxima (237,5 a $570 \mathrm{~W}$ ). O tratamento térmico foi realizado mediante a programação de potência do forno, de tal modo que a temperatura desejada da amostra fosse alcançada, após tempo inicial (rampa), e mantida por tempo determinado.

As 120 amostras tratadas foram analisadas quanto ao conteúdo de proteína bruta e umidade. Avaliou-se também a qualidade nutricional da proteína e efetuou-se o teste microbiológico de viabilidade, sendo as análises efetuadas em triplicata.

\subsection{CARACTERÍSTICAS FÍSICAS E QUÍMICAS DO LEITE DE LEVEDURA}

\section{- $\quad$ Teor de umidade}

O teor de umidade foi determinado pelo método gravimétrico, por diferença de peso após secagem em estufa a $105^{\circ} \mathrm{C}$, até peso constante - método 14.004 da AOAC (1984).

\section{- $\quad$ Teor de proteína bruta}

O teor de proteína bruta foi determinado pelo método micro-Kjeldahl, segundo método 13.011 da AOAC (1984). 


\section{- Teor de proteína solúvel}

Após tratamento em microondas, a suspensão foi separada por centrifugação, com $10.000 \mathrm{rpm}$ por 15 minutos, determinando-se no sobrenadante a proteína solúvel pelo método de Kjeldahl, depois de lavar o material insolúvel duas vezes com água.

\section{- $\quad$ Digestibilidade in vitro}

A digestibilidade in vitro foi determinada de acordo com o procedimento de AKESON \& STAHMAN (1964), que emprega sistema enzimático composto por pepsina/pancreatina. Alíquotas de $0,5 \mathrm{~g}$ de amostra foram incubadas inicialmente com pepsina, concentração de $3 \mathrm{mg} / \mathrm{mL}$ (relação enzima e substrato $=1: 22$ ) em ácido clorídrico $0,1 \mathrm{~N}, \mathrm{pH} 1,5$, por 3 horas a $37^{\circ} \mathrm{C}$, sob agitação constante. A seguir, a reação foi interrompida pela adição de $\mathrm{NaOH0}, 1 \mathrm{~N}$ para correção do $\mathrm{pH}$ em torno de 8,0 e as amostras incubadas pelo período de 24 horas, com pancreatina (concentração de $4 \mathrm{mg} / \mathrm{mL}$ ) em tampão fosfato $0,1 \mathrm{M}, \mathrm{pH} 8,0$ e temperatura de $37^{\circ} \mathrm{C}$. As proteínas não hidrolisadas pelo sistema enzimático foram precipitadas com ácido tricloroacético $30 \%$ e separadas por centrifugação (12.000 g/20 min). O volume do sobrenadante foi aferido para $50 \mathrm{~mL}$, determinando-se 0 nitrogênio pelo método semi-micro Kjeldahl.

O valor da digestibilidade da proteína, expresso em porcentagem, foi calculado pela relação entre as diferenças do nitrogênio contido no hidrolisado e no sistema enzimático (fornecido pelo branco), e a do nitrogênio total na amostra original e no sistema enzimático, segundo a equação (1):

Onde :

$$
\% \text { Digestibilidade }=\frac{\left(\mathrm{N}_{\mathrm{h}}-\mathrm{N}_{\mathrm{b}}\right)}{\left(\mathrm{N}_{\mathrm{t}}-\mathrm{N}_{\mathrm{b}}\right)} \times 100
$$

$$
\begin{aligned}
& N_{h}=\text { nitrogênio no hidrolisado; } \\
& N_{b}=\text { nitrogênio do branco (enzima); } \\
& N_{t}=\text { nitrogênio total. }
\end{aligned}
$$

\section{- Viabilidade das células}

Na determinação de viabilidade celular das leveduras foi utilizado o método de azul de metileno, descrito por LEE et al. (1981). A determinação de viabilidade para leveduras por este método é internacionalmente aceita pela European Brewery Convention (EBC), apresentando como vantagem, sua rapidez. A composição da solução de azul de metileno utilizada consta da Tabela 3. 
TABELA 3 - COMPOSIÇÃO DA SOLUÇÃO DE AZUL DE METILENO

\begin{tabular}{l|c}
\hline Discriminação & Quantidade \\
\hline $\mathrm{NaCl}$ & $4,5 \mathrm{~g}$ \\
$\mathrm{CaCl}_{2} \cdot 6 \mathrm{H}_{2} \mathrm{O}$ & $0,24 \mathrm{~g}$ \\
$\mathrm{NaHCO}_{3}$ & $0,1 \mathrm{~g}$ \\
Glicose & $5,0 \mathrm{~g}$ \\
Azul de metileno & $0,125 \mathrm{~g}$ \\
q.s.q. $\mathrm{H}_{2} \mathrm{O}$ destilada & $500 \mathrm{~mL}$ \\
\hline
\end{tabular}

As suspensões de células foram diluídas de modo a apresentar contagem de cerca de 150 células por quadrado na câmara de Newbauer. Misturouse $0,1 \mathrm{~mL}$ de suspensão com $0,9 \mathrm{~mL}$ de solução de azul de metileno, sendo as amostras transferidas com pipeta de Pasteur para a câmara. A contagem de células foi realizada em microscópio com campo claro e objetiva de imersão $(40 \mathrm{x})$. Para o cálculo do valor da viabilidade, expresso em porcentagem, utilizou-se a equação 2 :

$$
\mathrm{V}(\%)=\frac{\mathrm{N}^{\circ} \text { de células incolores }}{\mathrm{N}^{\circ} \text { de células incolores }+\mathrm{N}^{\circ} \text { de células azuis }} \times 100
$$

\section{RESUltAdOS E DISCUSSÃo}

\subsection{EFEITO DO TRATAMENTO TÉRMICO SOBRE A PROTEÍNA SOLÚVEL}

Os valores do rendimento de extração de proteínas das células tratadas em função do tempo e da temperatura são apresentados na Figura 1.

Pode-se observar que os rendimentos aumentaram inicialmente, alcançando valor máximo de $38,3 \%$ na temperatura de $110{ }^{\circ} \mathrm{C}$, por 15 minutos, e de $38,4 \%$ a $110^{\circ} \mathrm{C}$ por 30 minutos de aquecimento, a partir dos quais diminuíram gradualmente.

PACHECO (1996), trabalhando com células de Saccharomyces carslbergensis, tratadas por ruptura mecânica em moinho Dyno-mill, obteve entre 80 a $95 \%$ de rendimento. Porém o pH da solução foi ajustado para $8 \mathrm{com}$ o auxílio de solução de carbonato de sódio 10\%. Conforme SCHACHTEL (1981) a solubilidade das proteínas de levedura é baixa, quando comparada com outras proteínas vegetais como por exemplo a soja. A solubilidade é principalmente influenciada pelas etapas e condições de processamento para obtenção da proteína. Em trabalhos com células 
de levedura rompidas foi constatado que, na presença de sal $(0,5 \% \mathrm{NaCl})$ o comportamento da curva de solubilidade se altera, mudando o ponto isoelétrico de $\mathrm{pH} 4,5$ para 4,0, com solubilidade máxima ao redor de $\mathrm{pH}$ 6,0. Segundo HALÁSZ \& LASZTITY (1991) e LINDBLOM (1974),o tratamento térmico $\left(80{ }^{\circ} \mathrm{C}\right)$ em meio alcalino causou diminuição da solubilidade da proteína.

\section{FIGURA 1 - RENDIMENTO DE EXTRAÇÃO DA PROTEÍNA DAS CÉLULAS DE LEVEDURA TRATADAS COM MICROONDAS EM FUNÇÃO DO TEMPO E DA TEMPERATURA}

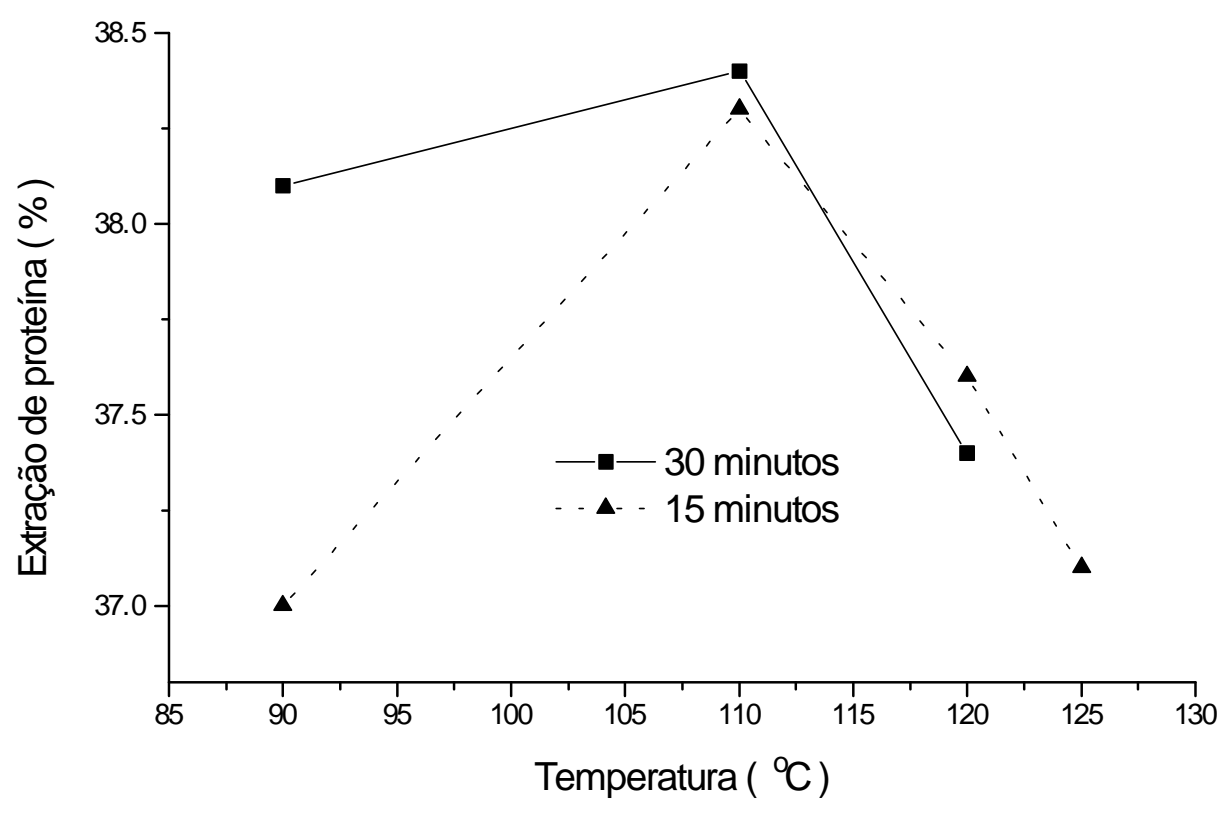

DZIMBA (1994) estudou a autólise de leveduras de panificação (Saccharomyces cerevisiae) e de cervejaria (Saccharomyces cars/bergensis), em temperaturas de $20,45,50,55$ e $60^{\circ} \mathrm{C}$. Verificou que o rendimento de extração de proteína aumenta até os $55^{\circ} \mathrm{C}$, mas que a $60{ }^{\circ} \mathrm{C}$ ocorre queda significativa. Segundo este autor, o efeito da temperatura a $60{ }^{\circ} \mathrm{C}$ pode desnaturar a proteína, provocando queda de mais da metade do valor obtido a $55^{\circ} \mathrm{C}$.

Conforme patente americana (CHAO, 1980) a autólise de levedura em geral ocorre em temperaturas entre 30 e $60{ }^{\circ} \mathrm{C}$. O processo é muito lento em baixas temperaturas, podendo requerer de 3 a 7 dias para se completar. Entre $50-55^{\circ} \mathrm{C}$, a digestão total pode ocorrer em 3 dias. Neste trabalho conseguiu-se extração por volta de $40 \%$, em altas temperaturas (90 a $120^{\circ} \mathrm{C}$ ) e tempo bem reduzido ( 15 a 30 minutos). 


\subsection{EFEITO DO TRATAMENTO TÉRMICO NA DIGESTIBILIDADE}

O valor de digestibilidade da proteína obtido para o leite de levedura, antes do tratamento foi de $29 \%$ e para a levedura seca comercial não tratada de $52 \%$. O valor encontrado para o produto comercial seco na usina foi relativamente baixo $(52 \%)$, em comparação com os obtidos por COZZOLINO (1982) - (80\%), FIALHO et al. (1983) - (70\%) e CABALLERO CORDOBA (1997) - (83\%).

Os valores da digestibilidade da proteína após o tratamento térmico com microondas constam da Figura 2. Observa-se que houve aumento da digestibilidade com aumento da temperatura, obtendo-se melhores resultados no tempo de 30 minutos. Porém, na temperatura de $120^{\circ} \mathrm{C}$ por 15 minutos alcançou-se o valor máximo de digestibilidade (85\%).

\section{FIGURA 2 - DIGESTIBILIDADE DA PROTEÍNA TRATADA POR MICROONDAS EM FUNÇÃO DO TEMPO E TEMPERATURA}

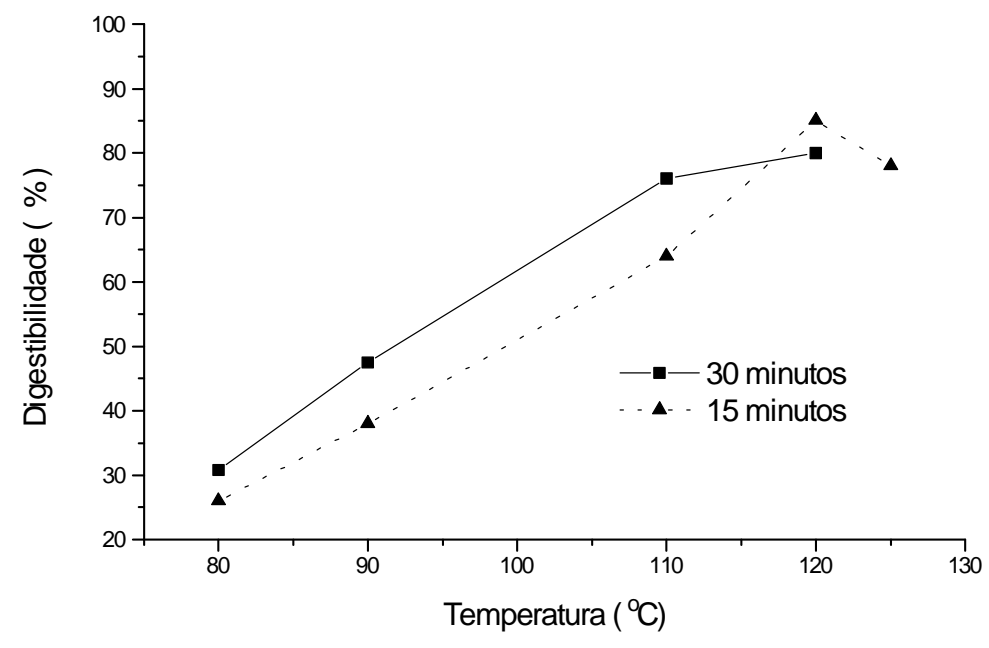

Segundo SGARBIERI (1996), praticamente, todas as proteínas são desnaturadas em temperatura acima de $40^{\circ} \mathrm{C}$. Tal afirmação corrobora os resultados de TANG et al. (1993), que estudaram a reologia de soluções de proteína concentrada.

O valor obtido (85\%) mostrou-se maior que o encontrado por BATTISTI et al. (1985) de 75,8\%, que o determinado por ZANUTO (1997) em levedura Saccharomyces $s p$. seca por atomizador ou por rolo rotativo $(83,79 \%)$, assim como o verificado por SOTO (1999) em leveduras secas (78,3\%). 


\subsection{EFEITO DO TRATAMENTO TÉRMICO NA VIABILIDADE CELULAR}

A viabilidade do leite de levedura antes do tratamento era de $77 \%$. Observou-se que a viabilidade das células (Figura 3 ) decresceu com aumento da temperatura, chegando-se a inativação total (viabilidade zero $\%$ ) na temperatura de $110{ }^{\circ} \mathrm{C}$, o que significa o rompimento total das células da levedura. Estes resultados são compatíveis com os apresentados por SANTIM (1996), trabalhando com leveduras de Saccharomyces cerevisiae seca e ativa do tipo comercial para panificação. Este autor reportou que as células foram inativadas a $121^{\circ} \mathrm{C}$ por $30 \mathrm{~min}$, com aquecimento convencional em autoclave.

Segundo GHIRALDINI \& ROSSELL (1996), no processo usado pela indústria que trabalha com leveduras, a termólise ocorre a $105^{\circ} \mathrm{C}$ por 15 minutos, com vapor vivo em coluna de evaporação. $O$ teor de digestibilidade da amostra de levedura em pó acusou valor relativamente baixo de $52 \%$.

\section{FIGURA 3 - VIABILIDADE DE CÉLULAS TRATADAS POR MICROONDAS EM FUNÇÃO DO TEMPO E TEMPERATURA}

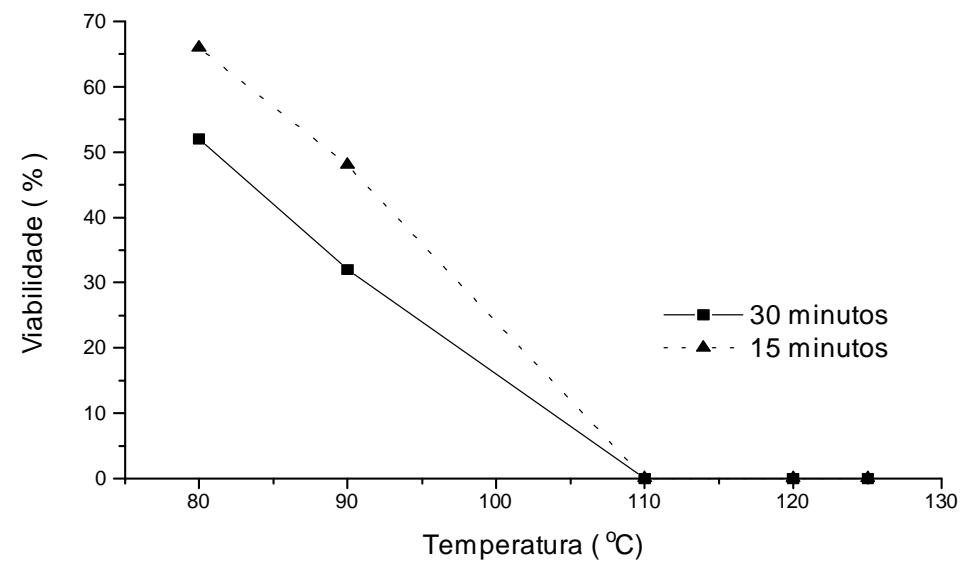

\section{CONCLUSÃO}

O tratamento térmico com microondas melhorou a digestibilidade da proteína. A levedura que apresentou resultado inicial na faixa de $29 \%$ teve este valor aumentado em $190 \%$ após o tratamento térmico (85\%).

$\mathrm{Na}$ extração da proteína solúvel obteve-se rendimento de extração de apenas $38 \%$, provavelmente, devido a desnaturação e precipitação de proteína, junto com as paredes e fibras das células. No uso para ração animal e como fonte de proteínas celulares, o tratamento térmico em 
microondas pode ser usado com vantagem face ao tempo reduzido do processo e a qualidade nutricional superior das proteínas em relação ao sistema convencional. Entretanto, o método não é recomendável para o uso de proteínas em indústria alimentícia com propriedades funcionais ativas (tais como, propriedade emulsificante, espumante, solubilidade, capacidade de geleificação), devido ao seu elevado percentual de desnaturação protéica.

\section{Abstract}

The thermolysis of yeasts Saccharomyces cerevisiae by using microwave oven were applied, using temperatures and exposition times as variables. The thermal effect of the cells (thermolysis) was the researched response, by verifying the protein extraction yield, the nutritional evaluation (digestibility) and cell viability. Values of $38 \%$ protein extraction, $32-85 \%$ protein digestibility and zero cell viability were achieved.

\section{REFERÊNCIAS}

1 AOAC. Official methods of analysis of the AOAC International. Washington D.C., 1984.

2 AKESON, W.R.; STAHMANN, M.A. A pepsin pancretin digest index of protein quality evaluation. Journal of Nutrition, Bethesda, v.83, n.2, p. 257-261, 1964.

3 BATTISTI, J.A; PEREIRA, J.A.A.; COSTA, P.M.A.; ROSTAGNO, H.S. Composição química e valores energéticos de alguns alimentos para suínos com diferentes idades. Revista Soc. Brasileira Zootecnia, v. 4, p. 141-151, 1985.

4 BRESSANI, R. The use of yeast in human foods. In: MATELLES, R.I.; TANNEMBAUN, S.R. Single-cell protein. Cambridge: The M.I., 1968. p. 90121.

5 CABALLERO CORDOBA, G.M. Levedura de cervejaria (Saccharomyces sp): composição, valor protéico e avaliação de toxicidade subcrônica em células integras, células mecanicamente rompidas e concentrado protéico. Campinas, 1997. 148p. Dissertação (Mestrado), UNICAMP, Faculdade de Engenharia de Alimentos.

6 CARVALHO, L.C.C. Ethanol program in Brazil: 25 years or near one century? WORLD SUGAR FARMERS CONFERENCE, $7^{\text {th }}$., Durban, South Africa, 1015 September, 2000. Proceedings... Durban: World Association of Beet and Cane Growers, 2000. (Disponível http://www.ifap.org/wabcg/durban/EthnlBrz.htm).

7 CHAO, K.C.; Mc CARTHY, E.F.; Mc CONEGHY, G.A. Yeast autolysis process. Patente 4, 218, 481. EUA, 19 Ago 1980. 
8 COZZOLINO, S.M.F. Valor nutricional da biomassa de Saccharomyces cerevisiae: estudos em gerações sucessivas de ratos. São Paulo, 1982. 147 p. Tese (Doutorado), Universidade de São Paulo, Faculdade de Ciências Farmacêuticas.

9 DZIMBA, F.E.J.M. Obtenção e avaliação de extratos protéicos por autólise das leveduras Saccharomyces cerevisiae e Saccharomyces carlsbergensis. Campinas, 1994. 105 p. Dissertação (Mestrado), Universidade de Campinas, Faculdade de Engenharia de Alimentos.

10 ENGLER, C.R. New method of measuring cell-wall rupture. Biotechnology \& Bioengineering, New York, v. 21, n. 10, p. 1861-1869, 1979.

11 FIALHO, E.T.; GOMES, P.; ALBINO, I.F.T.; COSTA, V. Determinação dos valores de composição química e de digestibilidade de alguns ingredientes nacionais para suínos. R. Soc. Bras. Zootecnia, v. 12, n. 2, p. 337-356, 1983.

12 GHIRALDINI, J. A.; LAHR FILHO, D.; ROSSEL, C.E.V. Estudos de otimização da recuperação de biomassa de levedura em destilarias. In: WORKSHOP PRODUÇÃ̂O DE BIOMASSA DE LEVEDURA: UTILIZAÇÃO EM ALIMENTAÇÃO HUMANA E ANIMAL, 28 ago. 1996. Campinas: ITAL, 1996. p.59-67.

13 HALÁSZ, A.; LÁSZTITY. Use of yeast biomass in food production. Boca Raton: CRC Press, 1991. $312 \mathrm{p}$.

14 HEDENSKOG, G.; MOGREN, H. Some methods for processing of single-cell protein. Biotechnology and Bioengineering, New York, v.15, n.1, p. 129142, 1973.

15 KIHLBERG, R. The microbe as source of food. R. Microbiol., v. 26, p. 427466, 1972.

16 KINSELLA, J. E.; SHETTY, H.J. Yeast proteins recovery, nutritional and functional properties. Adv. Exp. Med. Biol. v.107, p. 797-825, 1978.

17 KRIDER, J. L.; CONRAD, J.H.; CAROL, W.W. Swine production. $8^{\text {th }}$ ed. New York: Mc Graw Hill, 1982.

18 LEE, S.S.; ROBINSON, F. M.; WANG, H.Y. Rapid determination of yeast viability. Biotechnology and Bioengineering Symposium, n.11, p.641-649, 1981.

19 LINDBLOM, M. The influence of alkali and heat treatment on yeast protein. Biotechnology and Bioengineering, v.16, p.1495-1506, 1974.

20 MARSAIOLI, J. A. Desenvolvimento de tecnologia de aplicação de microondas em secador cilíndrico-rotativo combinado com ar quente para produtos granulados. Campinas, 1991. 197 p. Tese (Doutorado), Universidade de Campinas, Faculdade de Engenharia de Alimentos. 
21 MOURA, E.C.U. Fontes protéicas não convencionais: perspectivas do seu emprego na alimentação. In: NOBREGA, F.J. Desnutrição intrauterina e pós natal. 2. ed. São Paulo: Panamed, 1986. p. 43-63.

22 OKEZIE, B. O; KOSIKOWISKI, F. V. Extractibility and functionally of protein from yeast grow on cassava hydrolysate. Food Chemistry, Banking, v.7, n.1, p.7-18, 1981.

23 PACHECO, M.T.B. Propriedades funcionais, nutricionais e toxicológicas de concentrados protéicos de levedura (Saccharomyces sp), obtido por diferentes processos de extração. Campinas, 1996. 158 p. Tese (Doutorado), Universidade de Campinas, Faculdade de Engenharia de Alimentos.

24 REED, G.; NAGODAWITHANA, T.W. Yeast technology. New York: Van Nostrand Reinhold, 1991. 378 p.

25 REED, G.; PEPPLER, H.J. Yeast technology. Westport, Conn.: AVI, 1973.

26 SANTIM, A P. Estudo da secagem e inativação de leveduras Saccharomyces cerevisiae. Florianópolis, 1996. 150 p. Dissertação (Mestrado), Departamento de Eng. Química, Universidade Federal de Santa Catarina.

27 SCHACHTEL, A.P. Effects of preparative process on the composition and functional properties of protein preparations from Candida utilis. Journal of Food Science, v. 46, n. 2, p. 377-382, 1981.

28 SGARBIERI, V.C. Proteínas em alimentos protéicos: propriedades, degradações, modificações. São Paulo: Varela, 1996. 517 p.

29 SOTO, W.L.C. Digestibilidade da levedura desidratada e efeitos da sua utilização sobre a morfologia intestinal, atividade das enzimas digestivas e desempenho de suínos. Jaboticabal 1999, 82 p. Tese (Doutorado), UNESP, Faculdade de Ciências Agrárias e Veterinárias.

30 STARON, T.; PERRIN, L.;THIROUIN, D.; FRERE, G. Le traitement des produits biologiques alimentaires par les microondes. Industries Alimentares et Agricoles, n. 12, p. 1305-1312, 1980.

31 TANG, Q.; MUNRO, P.A.; McCARTHY, O.J. Rheology of whey protein concentrate solutions as a function of concentration, temperature, $\mathrm{pH}$ and salt concentration. Journal Dairy Research, v. 60, n.3, p. 349-361, 1993.

32 VANANUVAT, P.; KINSELLA, J. E. Aminoacid composition of protein isolates form Saccharomyces fragilis. J. Agric. Food Chem. v.23, p.595-597, 1975.

33 ZANUTTO, C. A utilização de levedura de recuperação (Saccharomyces sp) seca por "spray dryer" ou por rolo rotativo na alimentação de leitões na fase inicial. Maringá, 1997. 53 p. Dissertação (Mestrado), Universidade Estadual de Maringá. 